\title{
Bioenergy Special Issue: International Conference on Bioenergy Technologies and Joint Symposium with AIChE Forest Products Division, Nanjing, China, October 2012
}

\author{
J. Y. Zhu • Z.-H. Yuan • J. C. Jiang
}

Published online: 30 July 2013

(C) Springer Science+Business Media New York (outside the USA) 2013

Lignocellulosic biomass, such as agriculture residue, historically has been an energy source in many rural areas. This is especially true in China, where not many years ago rural families relied on rice and wheat straw or corn stover as energy sources for cooking. Agriculture residue has also been used for biogas production in China for several decades, and combustion and gasification of municipal waste have also been a source of energy. Rapid economic development in the past two decades has raised concerns over energy supply and the environmental impact of fossil fuel, which has led the Chinese government to invest heavily in research and development for bioenergy production from lignocellulloses. Since 1990, total investment has been more than 1 billion RMB. Chinese Academy of Sciences (CAS) established the Qingdao Institute of Bioenergy and Bioprocess Technology (QIBEBT) with an initial investment of US \$50 million. The QIBEBT focuses on biomass energy research and technical explorations, complementing the bioenergy research efforts at the Guangzhou Institute of Energy Conversion of CAS, which focuses on process engineering. The QIBEBT has recently expanded to a second phase with more investments. This special issue is based on selected papers presented at the 2012 International Conference on Bioenergy Technologies and Joint Symposium with the American Institute of Chemical Engineers (AIChE) Forest Products Division held in Nanjing, China. The biannual conference sponsored by the Biomass Energy Technical Committee of China Renewable Energy Society is one

J. Y. Zhu $(\bowtie)$

Forest Products Laboratory, USDA Forest Service,

Madison, WI, USA

e-mail: jzhu@fs.fed.us

\section{Z.-H. Yuan}

Guangzhou Energy Conversion Institute, Chinese Academy of

Sciences, Guangzhou, China

J. C. Jiang

Research Institute of Chemical Industry of Forest Products,

Chinese Academy of Forestry, Nanjing, China of the largest showcases of bioenergy research and development in China. Co-sponsorship by the Forest Products Division of AIChE enhanced participation in the conference.

This special issue reveals that current bioenergy research in China is no longer limited to traditional biogas, combustion, and gasification. It also involves biochemical, catalytic conversion, and new plant breeding. Also ongoing is research involving coproduct development through the biorefinery concept. Yang et al. from Capital Normal University (Beijing China) reported onestep saccharification and fermentation by expressing AGA1 gene of native a-agglutinin into the genomes of Saccharomyces cerevisiae Y5. Mu et al. from Georgia Institute of Technology conducted a review on upgrading lignin pyrolysis oil. Hu et al. of Northeastern Forestry University discussed thermal energy storage using nanocapsules with carboxymethyl cellulose.

We hope that through this special issue, readers get a glimpse of bioenergy research in China. We also hope that this issue can help promote international research collaboration in bioenergy. Finally, we hope that readers consider using BioEnergy Research as their primary source for research and publication. We see tremendous growth of the journal in terms of both numbers and quality of papers published as it enters its sixth year of publication.

We thank the authors for contributing to BioEnergy Research in a timely manner. We also thank the following Guest Associate Editors for overseeing and editing manuscripts for the issue: Prof. Yulin Deng of Georgia Institute of Technology, Dr. Bruce Dien of USDA Agriculture Research Service, Prof. Zhen Fan of the Chinese Academy of Sciences, Profs. Troy Runge and Xuejun Pan of University of Wisconsin, Prof. Sunkyu Park of North Carolina State University, Profs. Xiao Zhang and Jinwen Zhang of Washington State University, Prof. Nathan Mosier of Purdue University, Prof. Xuebing Zhao of Tsinghua University, Prof. Jie Bao of East China University of Technology, Dr. Ronald Zalesny, Jr., of USDA Forest Service, Prof. Peter van Walsum of University of Maine, and Prof. Donald Rockwood of University of Florida. 